\title{
Lean Supply Chain Planning: A Performance Evaluation through Simulation
}

\author{
Matteo Rossini and Alberto Portioli Staudacher \\ Politecnico di Milano, Management Engineering Department, Milano, Italy
}

\begin{abstract}
Nowadays companies look more and more for improving their efficiency to excel in the market. At the same time, the competition has moved from firm level to whole supply chain level. Supply chain are very complex systems and lacks of coordination among their members leads to inefficiency. Supply chain planning task is to improve coordination among supply chain members. Which is the best planning solution to improve efficiency is an open issue. On the other hand, Lean approach is becoming more and more popular among managers. Lean approach is recognize as efficiency engine for production systems, but effects of Lean implementation out of single firm boundaries is not clear. This paper aims at providing a theoretical and practical starting point for Lean implementation in supply chain planning issue. To reach it, a DES simulation model of a three-echelon and multi-product supply chain has been set. Lean management is a very broad topic and this paper focuses on two principles of "pull" and "create the flow". Kanban system and setup-time and batch-size reductions are implemented in the lean-configured supply chain to apply "pull" and "create the flow" respectively. Lean principles implementations have been analyzed and compared with other supply chain planning policies: EOQ and information sharing (Visibility). Supported by the simulation study, this paper points Lean supply chain planning is a competitive planning policies to increase efficiency.
\end{abstract}

\section{Introduction}

In In recent years, the competition is moved from firm vs firm to supply chain vs supply chain [1]. Competition continuously increases and pressures on the performances of the supply chain's members: a great emphasis is given to efficiency and managers are looking for cost reduction everywhere in companies [2]. There are many opportunities to reduce inefficiencies. Main inefficiencies lead to excess of inventory, backlog orders, supply and transportation extra-costing along the chain [3]. Supply chain planning is one of the major tasks for optimizing production, inventory and transportation processes [4].

Lean Management is becoming more and more popular among supply chain managers. The main feature of lean approach is to reduce every type of waste present in the production flow whether it means material waste, time waste or activity waste. It is largely demonstrated that lean approach implementation leads to cost reductions, higher quality level and shorter delivery time in a company [5].

In what direction and how much Lean approach influences the whole supply chain is not well defined [6]. This paper investigates the impact of Lean implementation along a supply chain. The purpose of this research work is to study which impacts has lean approach when implemented at a supply chain level. To achieve this, a simulation model of a multi-product and three-echelon supply chain has been implemented. This study deals with the analysis of supply chain's performance comparing Lean supply chain with two other supply chain planning policies: EOQ and Visibility. In Section 2, a brief literature review of supply chain planning and lean management themes is proposed. Section 3 defines the experimental design, where simulation model and planning policies descriptions and plan of experiments are presented. The outcomes of simulation study are discussed in the Section 4.

\section{Literature review}

Supply chain planning (SCP) is a complex and difficult task particularly because it involves different actors in different companies. SCP objective is to improve coordination and integration among members of the supply chain [4], [7]. In the next paragraph Visibility that is one of the most famous SCP policy is discussed. The second paragraph briefly discusses the literature of Lean management.

\subsection{Visibility}

Visibility leads to SC coordination improvement by information sharing practice among SC members [8]. Information sharing about inventory position of SC warehouses and about the members' orders policy helps 
actors of supply chain to plan their production satisfying customer demand and increasing efficiency [9], [10]. The literature of visibility is very broad.

Lee, in [9], and Cachon, in [10], studied the impact of visibility implementation on bullwhip effect in a SC and both showed that visibility reduce bullwhip effect and inventory level in the system.

Gavirneni, in [11], [12], explored different degree of visibility in a two-echelon SC. He demonstrated that the higher the visibility degree is the greater the $\mathrm{SC}$ benefits are in terms of logistic costs and inventories. Bottani, in [13], made a similar simulation study analysing the impact of different visibility degrees on different SC configurations. Different studies simulated the effects that visibility could have on demand forecasts accuracy of SC players [14]. In another work, Gavirneni simulated a twoechelon SC and demonstrated that most profitable order policy change whether or not Visibility is implemented: under no-visibility $\mathrm{SC}$ the most efficient order policy resulted $(\mathrm{s} ; \mathrm{S})$ while under visibility $\mathrm{SC}$ the most efficient order policy is $(\mathrm{r} ; \mathrm{Q})$.

\subsection{Lean management}

The lean management approach is famous for the struggle against the waste [15]. What is lean is difficult to define, it is possible to state that is a philosophy of work that focuses on what is relevant for the customer [16]. The purpose of lean approach is to improve overall levels of productivity and product quality, waste reduction, integration and interaction across functional departments, and improved work force autonomy. The traditional field of application of lean approach is the manufacturing firm operations, but recently lean academics and lean specialists are moving their attention to other fields that could be positively affected by lean. Supply chain is one of this new fields for Lean [6]. The term Lean supply refers to the extension of lean principles throughout the supply chain, both downstream and upstream [17] Lean supply chain is not properly a new field for Lean. In the past, Lean supply chain appeared in literature under different names: lean logistics, lean distribution, lean supply and lean enterprise. Seminal works have studied which are the practices that "considered Lean enterprises" adopt with their supplier and their customer [18]-[20]. There is a lack in literature of papers that discuss Lean supply chain with quantitative analysis focusing on planning issue.

Up to now little is known about the possible implications of Lean principles implementation for supply chain planning issue, in particular on inventory control.

In the next section it is described the experimental design set to fill this lack of knowledge.

\section{Experimental design}

Trough simulation tool is possible to reproduce models that are close to the reality and to analyse complex systems with a quantitative viewpoint [21]-[24].
A simulation study has been set up to improve our understanding of lean supply chain. To evaluate lean SC planning performance, a comparison with other SC planning policies is performed: Lean is compared with traditional EOQ policy and with Visibility policy.

The model used in the simulation study has been develop through a Discrete Event Simulation software (Rockwell Arena) and it is kept as basic as possible to avoid any noise that might cloud the sight on causes and effects.

\subsection{Supply chain model}

The simulation model represents a three echelons supply chain composed by four suppliers, a manufacturer and a retailer.

An input warehouse, a production phase and an output warehouse compose suppliers and manufacturer stages. Retailer stage is a distributor, so it does not process items. An infinite stock at suppliers' input buffers is assumed. The production systems stages a single machine where the items are processed. Many authors have used similar settings to understand the effect of SC planning policies on inventories in single product supply chains [10], [25], [26].

There are 24 different products from 4 different product families in the supply chain. One product family consists of 6 different products. Each of the suppliers is responsible to produce one product family. However, the suppliers are not fully dedicated to this supply chain; they produce other products for other supply chains as well. The manufacturer works all the 24 products and its operations are fully dedicated to this supply chain.

Multi-product SC and three-stage supply chain can provide valuable insights into managing complex systems efficiently.

An infinite number of trucks are available for the transport of finished and semi-finished products and the lead-time to transport an item to the next stage is deterministic and equal to two days.

Trucks leave the stage at the end of the day and shipped items are available to the next stage two days later, at the beginning of the day.

Everyday final customer demands finished product to the retailer and she has to satisfy the demand in MakeTo-Stock logic. The retailer has to provide before the shipment time (basically before the end of the day) the demanded pieces. If she does not satisfy the demand there is the stock-out and so the back-log of the order. The way how supply chain members place orders depends on the specific supply chain policy. In the supply chain all the components use the same planning policy. The planning policies studied in this paper are described below.

\subsection{SC planning policies}

This research work aims to analyse the SC performance while SC has implemented lean approach. Two different SC planning policies are compared with Lean SC planning: Economic Order Quantity (EOQ) and Visibility (VIS). EOQ policy is the basic level of the planning 
policy task, it is recognize as the first attempt of inventory control optimization. In the major part of the planning simulation works it is used as benchmark. The Visibility approach concerns information sharing practice and it is one of the most known approach to improve the planning function in a system.

\subsubsection{EOQ}

The EOQ approach is that all the SC members follow the $(r, Q)$ policy. Every warehouse is exposed to a continue check: when the inventory-position goes down a certain level (reorder point), an order is placed upstream to the previous warehouse. If it is an internal order, the production of a batch starts, if it is an inter-stages order, the shipping. The order size and the reorder point could be different for each warehouse and they are fixed during the single replication.

The inventory position is calculated as: Inventory position $=$ inventory level + ordered items but none arrived - backlog orders [27].

\subsubsection{Visibility}

Logic of the visibility approach exploits the information sharing among SC members. While visibility is operating, every stages know the inventory position of the downstream stage and can take advantage of that [11], [12], [26]-[28].

By means of this information, the manufacturer is able to postpone the production (optimizing production timing) and so reduces the average WIP.

In this research work the visibility policy bases on the policy developed by Datta and Christopher [29].

\subsubsection{Lean}

Referring to the lean principles explained by Womack and Jones [15], this paper tests "pull strategy" and "create the flow". "Pull" principle is implemented along the supply chain through a kanban system implementation in all SC stages: the production starts only if there is a consumption of material at the downstream stage. "Create the flow" aims at a flow as levelled as possible, without any kind of interruption. The batch-size and setup time reduction represents this principle in the simulation model.

Table 1. Supply chain planning policies

\begin{tabular}{|l|l|l|l|}
\hline & EOQ & \multicolumn{1}{|c|}{ Visibility } & \multicolumn{1}{c|}{ Lean } \\
\hline & & & $100 \%($ Lean_100\%) \\
Batch-size & $100 \%$ & $100 \%$ & $80 \%($ Lean_80\%) \\
and & (EOQ) & (VIS) & $60 \%($ Lean_60\%) \\
setup time & & & $40 \%($ Lean_40\%) \\
& & & $20 \%($ Lean_20\%) \\
\hline
\end{tabular}

Lean_100\% is the Lean SC planning policy with the implementation of pull principle. Lean_80\%, Lean $60 \%$, Lean_40\% and Lean $20 \%$ are Lean SC planning policies with the implementation of "pull" principle and implementation of "create the flow" principle (respectively $20 \%, 40 \%, 60 \%$ and $80 \%$ batch size and setup time reductions). A brief resume of SC planning policies adopted in this simulation study is presented in the Table 1.

\subsection{Experimental parameters}

Supplier and manufacturer stages have finite production capacity. Moreover supplier is not dedicated only to this supply chain so every day it dedicates a variable amount of time to produce pieces for the manufacturer $(65 \%$ on average). Process times and demand rates have been defined in order that Manufacturer and Supplier are $80 \%$ saturated. This saturation capacity value is a good compromise between what there is in literature, i.e. [26], and in the real world.

Like in the most part of SC simulation works the daily demand follows a Normal distribution.

Many papers stated that demand variability is a relevant parameter on SC planning policy performance. Due to this three different level of demand variability are studied. The coefficient of variation of the daily demand can be low $($ c.v. $=0,4)$, medium $($ c.v. $=0,6)$ and high (c.v. $=0,8)$.

The service level of the SC is measured by the mean of the service levels of the single warehouses. The single warehouse service level is the ratio between the number of days of stockout and the overall number of days in the simulated period. The warehouse is in stockout whether it has not handled all the orders at the end of the day. This research work tested the supply chain performance of different service levels (from $92 \%$ to $99 \%$ ).

The inventory level performance considered measures the amount of WIP along the entire SC.

The simulation runs for a period of 2050 days or 410 weeks with the first 50 days as the initialisation period, the statistics from which were not used in the results.

\subsection{Plan of experiments}

The simulation study considers all the possible scenarios that derive from the combination of the experimental parameters such demand c.v. (3) and service level (15) and the values of experimental variables (7). This means that 315 scenarios are studied.

\section{Simulations results}

This section discusses the results of simulation study for each of the parameters investigated. Particular attention is paid to use the SC holistic point of view for service level and inventory level.

\subsection{Inventory level and service level}

It is noteworthy that service level affects inventory levels: the higher the required service level the higher the necessary inventory level is valid for all the SC planning policies. What is interesting to observe is the difference between policies. The Fig. 1 shows all inventory level curves that are related to different SC policies. EOQ SC 
curve starts at 6553 and arrives to 10024; Visibility SC starts at 5885 and arrives to 9262; Lean_100\% starts at 4473 and arrives to 7191 . Increasing service level from $93 \%$ to $99 \%$ EOQ SC inventory has increased by $53 \%$, Visibility SC inventory by $57 \%$ and Lean SCs $64 \%$. Service level affect similarly the inventory increase of EOQ and of Visibility: inventory difference at $99 \%$ service level and $93 \%$ for Visibility is $2,7 \%$ lower than for EOQ. It appears that service level affects much more Lean inventory level than Visibility inventory level.

Comparing the inventory values of extreme tested service levels in the graph (93\% and 99\%), Lean SC absolute inventory increase is at least 20\% lower than inventory increase for Visibility. According to this, it is possible to state that, increasing service level, Lean benefits against Visibility benefits increase and so Lean advantages increase in high service level contexts.

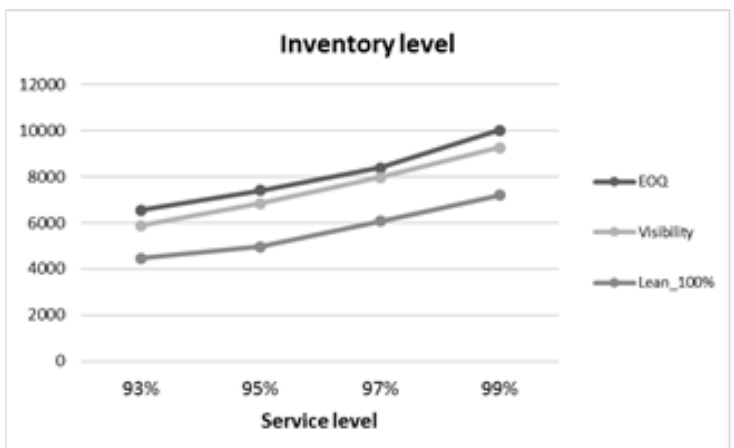

Figure 1. Inventory level curves for different service level.

\subsection{Inventory level and variability}

Coefficient of variation is relevant for inventory levels. As could been seen in the Figure 2, increasing coefficient of variation of final customer demand there is a general increase of inventory levels. EOQ curve starts at 7815 and increases to 8356 , Visibility curve starts at 7220 and increases to 7756 , Lean_100\% curve starts at 5361 and increases to 6013. Comparing inventory levels of $0,4 \mathrm{c.v}$. context and 0,8 c.v. context: EOQ SC inventory increase is $6,9 \%$, Visibility $\mathrm{SC}$ inventory increase is $7,4 \%$ Lean_100\% SC inventory increase is $12 \%$. Increasing the coefficient of variation, the relative increase of inventory is greater for Lean than for Visibility. However Lean is not only PULL but also set-up and lot size reduction. Therefore it is necessary to analyse the impact of such element.

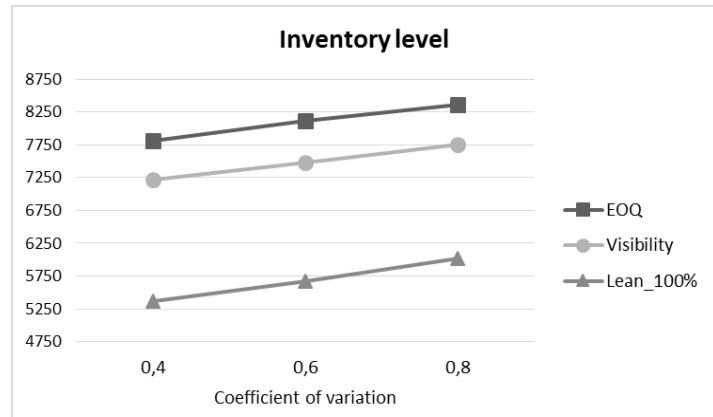

Figure 2. Inventory level curves for different coefficient of variation.

\subsection{Inventory level and setup time and batch-size reduction}

The average impact of batch-size reduction is given in the Figure 3. Implementing batch-size reduction, inventory level decrease is performed. $20 \%$ batch size reduction have been tested in this simulation work. Reducing batchsize a first time (or in other words changing from Lean_100\% to Lean_80\%) decreases inventory level by $17 \%$. The effect of second batch-size is $12 \%$ inventory reduction, the effect of third is 7\% and the effect of fourth is $10 \%$. The results show that setup-time reduction benefit on inventory levels is smooth: first batch-size reduction are more effective than the last ones. Moreover, it has been noted a positive effect of batch size and setup time reduction that smooths negative effects of variability on supply chain planning performances.

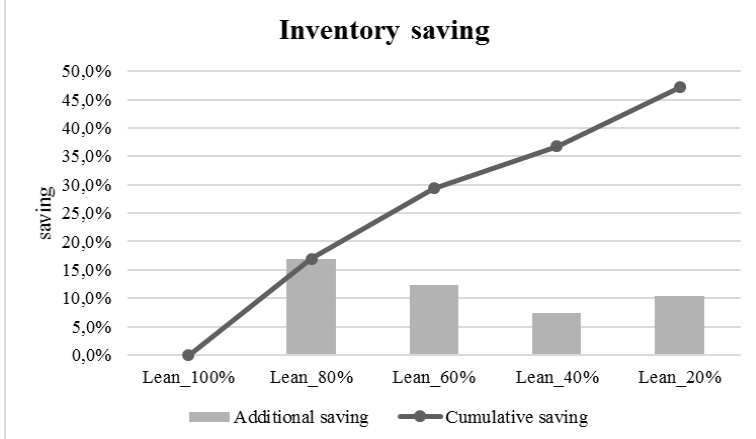

Figure 3. Inventory savings given by setup and batch reductions.

\subsection{Inventory savings}

An overview of inventory level saving for all the SC planning policies compared with EOQ is presented in fig 4. Visibility leads to an average 7,7\% inventory saving. Lean $100 \%$, Lean $80 \%$, Lean $60 \%$, Lean $40 \%$ and Lean_20\% respectively lead to $30,1 \%, 41,5 \%, 51,6 \%$, $56 \%$ and $63,5 \%$ inventory savings. Lean has always greater savings than visibility about inventories. The greater batch-size reduction is the greater the benefits of Lean are. However the effect of the batch size reduction is smooth, as previously discussed. According to the values of this simulation work, the Lean inventory savings are at least three times Visibility inventory savings. Thus, it is possible to conclude that Lean implementation impact on SC planning performances is very relevant and could lead to significant logistic cost improvements.

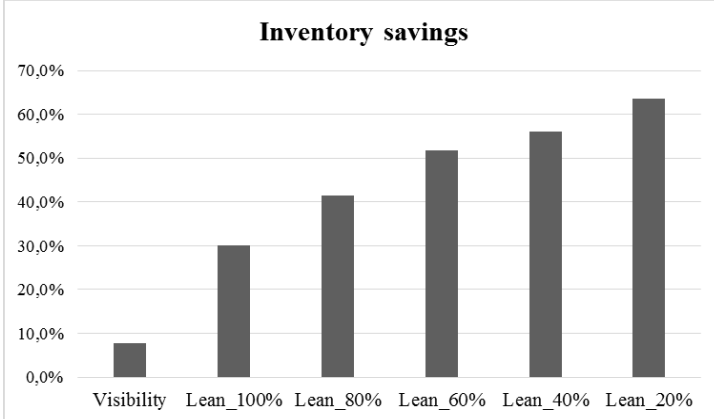

Figure 4. Inventory savings for different supply chain planning policies. 


\section{Conclusions}

This paper aims at improving foundations for lean supply chain implementation. A simulation study has been performed to support our considerations and to analyse impact of lean principles implementation under different contexts. The simulation study shows that Lean planning policy leads to high inventory savings. With the best performing Lean_20\%, the average inventory saving reaches to $63 \%$. The simulation also shows that Lean supply chain planning performs better than visibility and EOQ SCs in high service level contexts and high variability contexts.

The results have important managerial implications. When implementing a SC planning policy, the focus should be on specific parameters: there is a trade-off analysis to do because of the different impacts that Lean and Visibility have on the SC inventory carrying cost and transportation costs. Investments on setup-time and batch-size reduction deserve particular attention, and should be based on SC holistic point view. Therefore, this work could be an initial support to implement lean approach in SC's operations systems. The research has scientific implications with respect to the development of supply chain planning task. It provides insight into which sensitivities can be avoided. This simulation model is useful for further researches because it allows to replicate different supply chain planning policies and differently from the most part of the simulation models present in literature that study a single-product and two echelon supply chain, it simulates a multi-product and three echelon supply chain. The embedding of different transportation rules, different production capacity saturations should be added in future research.

\section{References}

1. M. W. McCarter and G. B. Northcraft, J. Oper. Manag., vol. 25, no. 2, pp. 498-511, (2007)

2. K. L. Sim and J. W. Rogers, Manag. Res. News, vol. 32, no. 1, pp. 37-49, (2009)

3. H. L. Lee, V. Padmanabhan, and S. Whang, "The Bullwhip Effect In Supply Chains 1 Abstract," vol. 38, no. 3, pp. 93-102, (1997)

4. J. Olhager, Int. J. Prod. Res., vol. 51, no. 23-24, pp. 6836-6843, (2013)

5. T. Melton, Chem. Eng. Res. Des., vol. 83, no. 6, pp. 662-673, (2005)
6. N. V. K. Jasti and R. Kodali, Int. J. Prod. Res., no. August, pp. 1-19, (2014)

7. M. Caridi, L. Crippa, A. Perego, A. Sianesi, and A. Tumino, Int. J. Prod. Econ., vol. 127, no. 2, pp. 372383, (2010)

8. P. A. Bartlett, D. M. Julien, and T. S. Baines, Int. J. Logist. Manag., (2008)

9. H. L. Lee, V. Padmanabhan, and S. Whang, Manage. Sci., vol. 43, no. 4, pp. 546-558, (1997)

10. G. P. Cachon and M. Fisher, Manage. Sci., vol. 46, no. 8, pp. 1032-1048, (2000)

11. S. Gavirneni, Manage. Sci., vol. 48, no. 5, pp. 644651, (2002)

12. S. Gavirneni, R. Kapuscinski, and S. Tayur, Manage. Sci., vol. 45, no. 1, pp. 16-24, (1999)

13. E. Bottani and R. Montanari, Int. J. Prod. Res., vol. 48, no. 10, pp. 2859-2886, (2010)

14. A. Angulo, H. Nachtmann, and M. A. Waller, J. Bus. Logist., vol. 25, no. 1, pp. 101-120, (2004)

15. J. P. Womack, D. T. Jones, and D. Roos, Bus. Horiz., vol. 35, no. 3, pp. 81-82, (1992)

16. S. Bhasin and P. G. Burcher, "Lean viewed as a philosophy," no. 2002, (2006)

17. A. Reichhart and M. Holweg, Int. J. Prod. Res., vol. 45, no. 16, pp. 3699-3722, (2007)

18. R. Lamming, Int. J. Oper. Prod. Manag., vol. 16, no. 2, pp. 183-196, (1996)

19. J. K. Liker and T. Y. Choi, Harvard Business Review, vol. 82, no. 12. pp. 104-113+149, (2004)

20. J. K. Liker and Y. Wu, Sloan Manage. Rev., no. Fall, pp. 81-93, (2000)

21. H. K. Chan and F. T. S. Chan, Int. J. Prod. Res., vol. 48, no. 10, pp. 2793-2819, (2010)

22. S. Terzi and S. Cavalieri, Comput. Ind., vol. 53, no. 1, pp. 3-16, (2004)

23. J. Košturiak and M. Gregor, Comput. Ind., vol. 38, no. 2, pp. 159-172, (1999)

24. E. Akçalı and S. Çetinkaya, Int. J. Prod. Res., vol. 49, no. 8, pp. 2373-2407, (2011)

25. F. Chen, Z. Drezner, J. K. Ryan, and D. Simchi-Levi, Manage. Sci., vol. 46, no. 3, pp. 436-443, (2000)

26. J. K. Kwak and S. Gavirneni, Int. J. Prod. Econ., vol. 132, no. 2, pp. 271-278, (2011)

27. F. Chen, Manage. Sci., vol. 44, no. 12-Part-2, pp. S221-S234, (1998)

28. W. Zhu, S. Gavirneni, and R. Kapuscinski, IIE Trans., vol. 42, no. 3, pp. 173-187, (2009)

29. P. P. Datta and M. G. Christopher, Int. J. Prod. Res., vol. 49, no. 3, pp. 765-803, (2011) 